\title{
Gravity wave intensity and momentum fluxes in the mesosphere over Shigaraki, Japan $\left(35^{\circ} \mathrm{N}, 1^{\circ}{ }^{\circ} \mathrm{E}\right)$ during $1986-1997$
}

\author{
N. M. Gavrilov ${ }^{1}$, S. Fukao ${ }^{2}$, T. Nakamura ${ }^{2}$ \\ ${ }^{1}$ Atmospheric Physics Department, Saint-Petersburg University, Petrodvorets, 192904, Russia \\ ${ }^{2}$ Radio Atmospheric Science Center, Kyoto University, Uji, 611-0011, Japan
}

Received: 22 March 1999 / Revised: 11 February 2000 / Accepted: 18 February 2000

\begin{abstract}
Averaged seasonal variations of wind perturbation intensities and vertical flux of horizontal momentum produced by internal gravity waves (IGWs) with periods $0.2-1 \mathrm{~h}$ and $1-6 \mathrm{~h}$ are studied at the altitudes $65-80 \mathrm{~km}$ using the MU radar measurement data from the middle and upper atmosphere during 1986-1997 at Shigaraki, Japan $\left(35^{\circ} \mathrm{N}, 136^{\circ} \mathrm{E}\right)$. IGW intensity has maxima in winter and summer, winter values having substantial interannual variations. Mean wave momentum flux is directed to the west in winter and to the east in summer, opposite to the mean wind in the middle atmosphere. Major IGW momentum fluxes come to the mesosphere over Shigaraki from the Pacific direction in winter and continental Asia in summer.
\end{abstract}

Key words: Meteorology and atmospheric dynamics (middle atmosphere dynamics; waves and tides) Ionosphere (ionospheric disturbances)

\section{Introduction}

Internal gravity waves (IGWs) are very important for the dynamical regime of the middle and upper atmosphere. Propagating from below and originating in the upper atmosphere, they can produce turbulence and substantial deposits of momentum and energy and influence the general circulation, thermal regime, and composition of the middle and upper atmosphere (Andrews et al., 1987). Therefore, IGWs have been studied extensively during last decades (see reviews by Fritts, 1984; Hirota, 1997; McLandress, 1998). Much information about IGWs has been obtained with radar techniques (Vincent, 1984; Fritts and Vincent, 1987; Ebel et al., 1987; Manson and Meek, 1993). Since 1986

Correspondence to: N. M. Gavrilov extensive studies of IGWs in the mesosphere have been performed with the middle and upper (MU) atmosphere radar at Shigaraki, Japan $\left(35^{\circ} \mathrm{N}, 136^{\circ} \mathrm{E}\right)$ (Tsuda et al., 1990; Nakamura et al., 1993a, b, 1996; Gavrilov et al., 1996, 1997). These observations use five radar antenna beams simultaneously (one vertical and four oblique) and give an opportunity to study the IGW intensity and components of vertical flux of horizontal momentum using traditional techniques (Vincent and Reid, 1983; Vincent and Fritts, 1987; Fukao et al., 1988).

Previous studies of IGW characteristics with the MU radar were made for relatively short intervals over a few years only, mainly from the beginning of the MU radar observations, started in 1986. Considering the entire set of the MU radar data we can expect substantial interannual variations of IGW intensity and momentum fluxes. Therefore, it is important to work out the mean characteristics averaged over the entire period of the MU radar observations, which could be considered as characteristics of wave climatology.

In the present work we use the data of the MU radar observations in 1986-1997 to obtain average IGW intensities and momentum fluxes at the altitudes 65$80 \mathrm{~km}$. In subsequent sections we describe the method of data analysis, results of IGW studies, and undertake some discussion of the results.

\section{Statistical analysis}

\subsection{Filtering the data}

During a day, at each altitude in the mesosphere, the MU radar provides a time series of Doppler velocity $v_{r j}\left(t_{i}\right)$ along the axes of the antenna beams pointed in five directions: vertically $(j=1)$ and inclined $10^{\circ}$ from zenith to the north, east, south, and west $(j=2,3,4$, and 5 , respectively). The nominal sampling interval is $\delta t=t_{i+1}-t_{i} \sim 2 \mathrm{~min}$, and height resolution is $\sim 0.3 \mathrm{~km}$. To filter out components belonging to different spectral frequency intervals, we use standard filtering by 
averaging the data over fixed time intervals, $T$, with window function:

$v_{f}(t)=\frac{1}{2 T} \int_{-T / 2}^{T / 2} v(t+\tau)\left(1+\cos \frac{2 \pi \tau}{T}\right) \mathrm{d} \tau$.

First, we calculate velocity average over three consecutive heights and then apply sliding filter Eq. (1) with $T=10 \mathrm{~min}$. This gives us values $\hat{v}_{r j}\left(t_{i}\right)$, which contain information about velocity variations with vertical and time scales larger than $\sim 1 \mathrm{~km}$ and $\sim 0.2 \mathrm{~h}$, respectively. To these values we apply sliding filter Eq. (1) with $T=1 \mathrm{~h}$ to obtain values $\tilde{v}_{r j}\left(t_{i}\right)$. After filtering them using Eq. (1) at $T=6 \mathrm{~h}$, we have values $\bar{v}_{r j}\left(t_{i}\right)$. The high frequency ( $W H$ - within hour) component, $v_{r j}^{(w h)}\left(t_{i}\right)$, and medium frequency $(M F)$ component $v_{r j}^{(m f)}\left(t_{i}\right)$ are calculated as follows:

$v_{r j}^{(w h)}\left(t_{i}\right)=\hat{v}_{r j}\left(t_{i}\right)-\tilde{v}_{r j}\left(t_{i}\right) ;$

$v_{r j}^{(m f)}\left(t_{i}\right)=\tilde{v}_{r j}\left(t_{i}\right)-\bar{v}_{r j}\left(t_{i}\right)$,

and contain information about wind variations with time scales $0.2-1 \mathrm{~h}$ and $1-6 \mathrm{~h}$ for $W H$ and $M F$ components, respectively.

The MU-radar mesospheric observations usually contain gaps in the data. Therefore, it is interesting to study the influence of such gaps on the transmission band width of used numerical frequency filters. Figure 1 represents average energy transmission functions of the $W H$ and $M F$ filters calculated for a number of model data sets using real MU-radar values of times and altitudes and model wind values represented by sinusoids of different frequencies. The phases of the model sinusoids were specified the same at all altitudes. Therefore, height averaging of the data over $1 \mathrm{~km}$ altitudes (see earlier) does not attenuate their amplitudes, and $H^{2}$ in Fig. 1 represents only effect of frequency filtering and effects of data gaps. Values shown on Fig. 1 are averaged over 30 model runs using data sets having less than $60 \%$ of gaps. One can see that

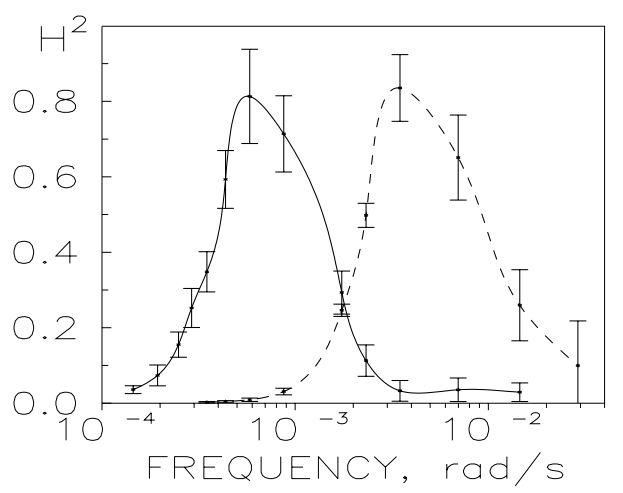

Fig. 1. Average spectral energy transmission functions of effective numerical filters used for $W H$ (dashed line) and $M F$ (solid line) filtering the MU radar data. Vertical bars show variances of the transmission functions due to different time and vertical distribution of real MU radar data with gaps the standard deviations of filter transmission functions due to data gaps are not very large (see vertical bars in Fig. 1). Hence the proposed filtering could be effective to separate different parts of wind variation spectra.

Continuous mesospheric observations with the MU radar usually last from 1 to 12 daytime hours. According to Eq. (2), the $W H$ component can be calculated for any data set longer then $1 \mathrm{~h}$, while calculation of $M F$ and mean components requires data sets longer than $6 \mathrm{~h}$.

\subsection{Calculating variances and momentum fluxes}

As is mentioned, the MU radar measures the components of the wind along one vertical and four oblique axes of the antenna beams. Both horizontal and vertical winds contribute to the oblique velocity components, so that

$v_{r 1}(t)=w(t) ;$

$v_{r 2}(t)=w(t) \cos \theta+v(t) \sin \theta ;$

$v_{r 3}(t)=w(t) \cos \theta+u(t) \sin \theta ;$

$v_{r 4}(t)=w(t) \cos \theta-v(t) \sin \theta ;$

$v_{r 5}(t)=w(t) \cos \theta-u(t) \sin \theta$,

where $\theta=10^{\circ}$ is the zenith angle of the inclined antenna beam, and $u, v$, and $w$ denote the wind components directed eastward, northward, and upward, respectively. The following formulae for the mean horizontal wind components can be obtained:

$u_{0}=\left(\overline{v_{r 3}}-\overline{v_{r 5}}\right) / 2 \sin \theta ; \quad v_{0}=\left(\overline{v_{r 2}}-\overline{v_{r 4}}\right) / 2 \sin \theta$

and for the wind variances:

$\overline{u^{\prime 2}}=\left(\overline{v_{r 3}^{2}}+\overline{v_{r 5}^{2}}\right) / 2 \sin ^{2} \theta-\overline{v_{r 1}^{2}} \cot ^{2} \theta$;

$\overline{v^{\prime 2}}=\left(\overline{v_{r 2}^{2}}+\overline{v_{r 4}^{2}}\right) / 2 \sin ^{2} \theta-\overline{v_{r 1}^{2}} \cot ^{2} \theta$;

where upper bars denote time averaging. Pairs of tilted antenna beams have been widely used to determine the components of vertical flux of horizontal momentum (Vincent and Reid, 1983; Fritts and Vincent, 1987; Reid, 1987; Fukao et al., 1988; Tsuda et al., 1990) using following expressions:

$F_{m x}=\overline{u^{\prime} w^{\prime}}=\left(\overline{v_{r 3}^{2}}-\overline{v_{r 5}^{2}}\right) / 2 \sin 2 \theta$,

$F_{m y}=\overline{v^{\prime} w^{\prime}}=\left(\overline{v_{r 2}^{2}}-\overline{v_{r 4}^{2}}\right) / 2 \sin 2 \theta$.

The module and azimuth (clockwise from the north) of the momentum flux are

$F_{m}=\left(F_{m x}^{2}+F_{m y}^{2}\right)^{1 / 2}$;

$\varphi_{m}=\arctan F_{m x} / F_{m y}$.

Substituting the quantities $v_{r}^{(w h)}$ and $v_{r}^{(m f)}$ into Eqs. (5)(7), we can obtain velocity variances and momentum fluxes produced by high- and medium-frequency parts of the spectrum of wind disturbances. 


\section{Seasonal variations of IGW characteristics}

The method described in Sect. 2 is used here to study seasonal variations of IGW intensity and momentum fluxes from the data of wind velocity measurements at the altitudes $65-80 \mathrm{~km}$ with the MU radar at Shigaraki, Japan $\left(35^{\circ} \mathrm{N}, 136^{\circ} \mathrm{E}\right)$ during $1986-1997$. For each day at each altitude we perform filtering Eqs. (1), (2) and extract the mean wind and $W H$ and $M F$ components described in Sect. 2. These components give information about wind variations with periods $0.2-1 \mathrm{~h}$ and $1-6 \mathrm{~h}$, respectively. To make the filtering more reliable we choose only data sets with gaps smaller than $60 \%$ gaps. This gives the filter transmission functions shown in Fig. 1. To calculate the mean wind and $M F$ component we use only daily data sets longer than $6 \mathrm{~h}$. Characteristics of $W H$ component are calculated for all data sets longer than $1 \mathrm{~h}$. With such requirements, the numbers of days of MU radar observations in 1986-1997 used in our analysis are 343 for the mean wind and $M F$ component and 427 for $W H$ component.

\subsection{Averaged IGW characteristics for 1986-1997}

To find seasonal variations averaged over the entire duration of the MU radar observations, the daily values of the mean wind, IGW variances and momentum fluxes have been averaged for each corresponding month over all years from 1986 to 1997 . The data is also averaged for two $6-\mathrm{km}$ thick layers centred at 70 and $75 \mathrm{~km}$. The layers have $1 \mathrm{~km}$ overlapping, therefore only $15-20 \%$ of the data is common to the two layers. Therefore, correlation of the results for the two layers should not be substantial. On the other hand, some increase in the data numbers helps to obtain more statistically reliable estimations of IGW characteristics for each of the layers. The obtained average seasonal variations of the mean wind, IGW intensity and momentum fluxes are shown in Fig. 2. One can see the change in the mean wind from eastward in winter to westward in summer typical for the mesosphere. Variances $\overline{u^{\prime 2}}, \overline{v^{\prime 2}}$ and $\overline{w^{\prime 2}}$ for $M F$ and $W H$ components shown in Fig. 2 have maxima in winter and in summer. Quantity $\overline{w^{\prime 2}}$ can contain a contribution from horizontal wind in addition to vertical wind component. Vertical flux of zonal momentum, $\overline{u^{\prime} w^{\prime}}$, is directed to the west in winter and to the east in summer, opposite to the mean wind (see Fig. 2). Seasonal variations of meridional momentum flux, $\overline{v^{\prime} w^{\prime}}$, in Fig. 2 are more complicated with some tendency to a prevailing northward direction in winter.

Described features of seasonal variations of the mean wind and IGW intensities have been observed previously with the MU radar (Tsuda et al., 1990; Nakamura et al., 1993a, b) and in other places (Vincent and Fritts, 1987; Manson and Meek, 1993; Nakamura et al., 1996). The main difference of our results from previous is in winter magnitudes of IGW parameters. Previous studies of IGWs with the MU radar (Tsuda et al., 1990; Nakamura et al., 1993a, b) were mainly based on the data for 1986-1989 and showed the winter
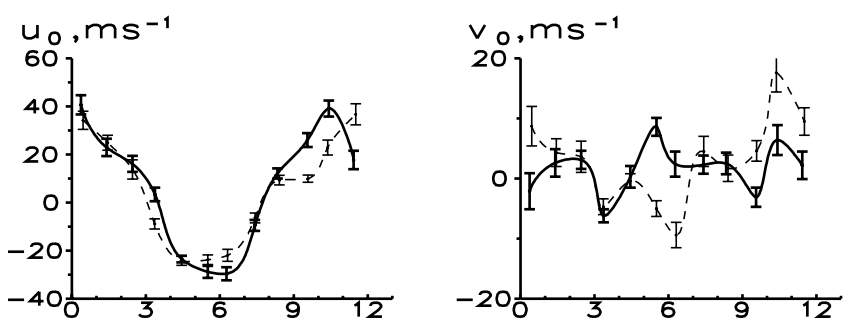

$\overline{u_{m f}^{\prime 2}}, m^{2} s^{-2}$
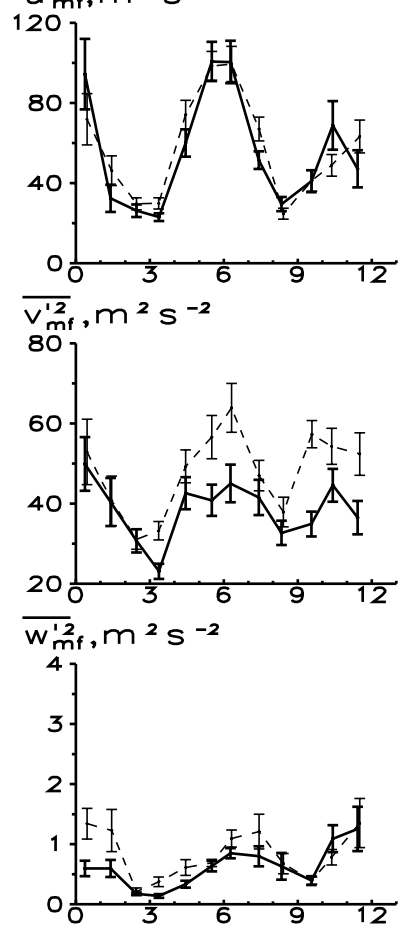

$\bar{u}^{\prime} w_{m f}^{1}, m^{2} s^{-2}$

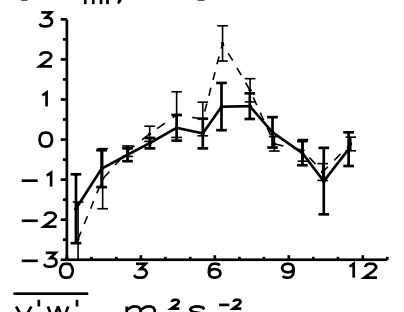

$\overline{u_{w h}^{\prime 2}}, \mathrm{~m}^{2} \mathrm{~s}^{-2}$
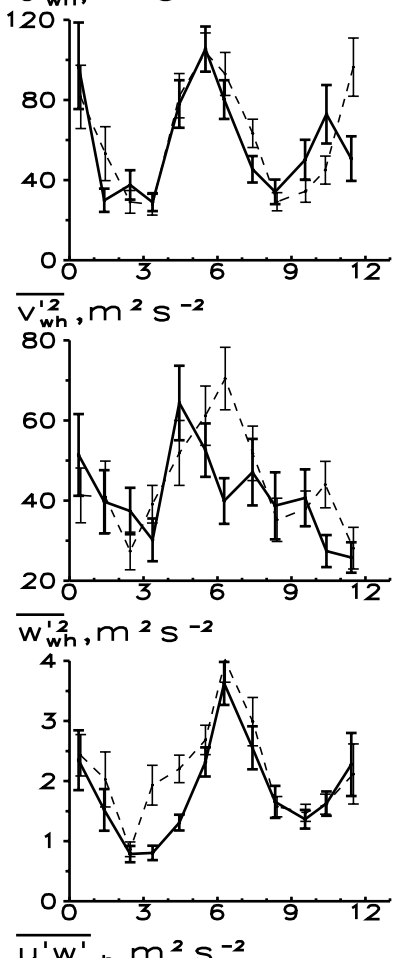

$\overline{u^{\prime} w_{w h}^{1}}, m^{2} s^{-2}$
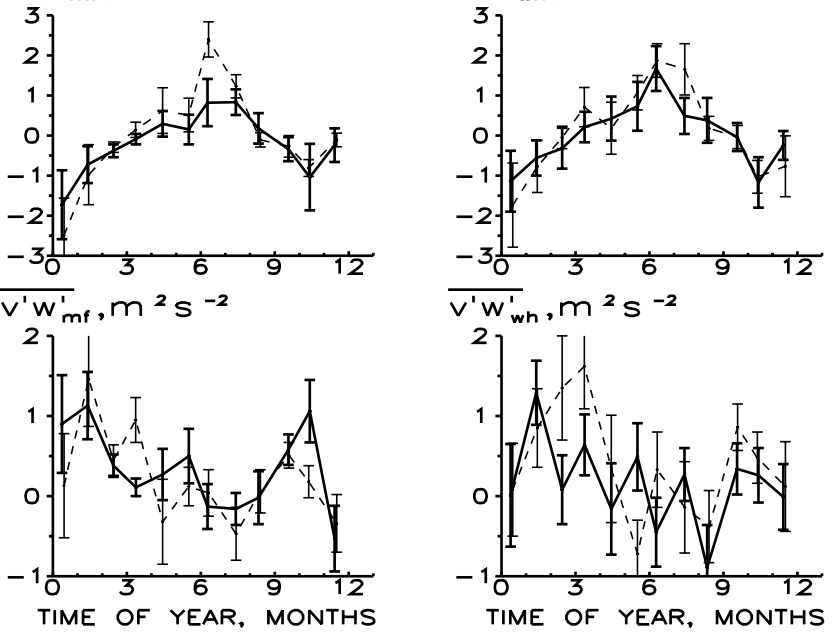

Fig. 2. Seasonal variations of the mean wind, variances of wind velocity and wave momentum fluxes averaged over 1986-1997 for $M F$ (left) and $\mathrm{WH}$ (right) components at the altitudes $70 \mathrm{~km}$ (solid lines) and $75 \mathrm{~km}$ (dashed lines)

maximum of IGW intensity to be weaker than the summer maximum.

Analysis of Sect. 3.3 shows that the winter values have substantial inter-annual variations, and Fig. 2 shows that the averages over 12 years winter IGW 


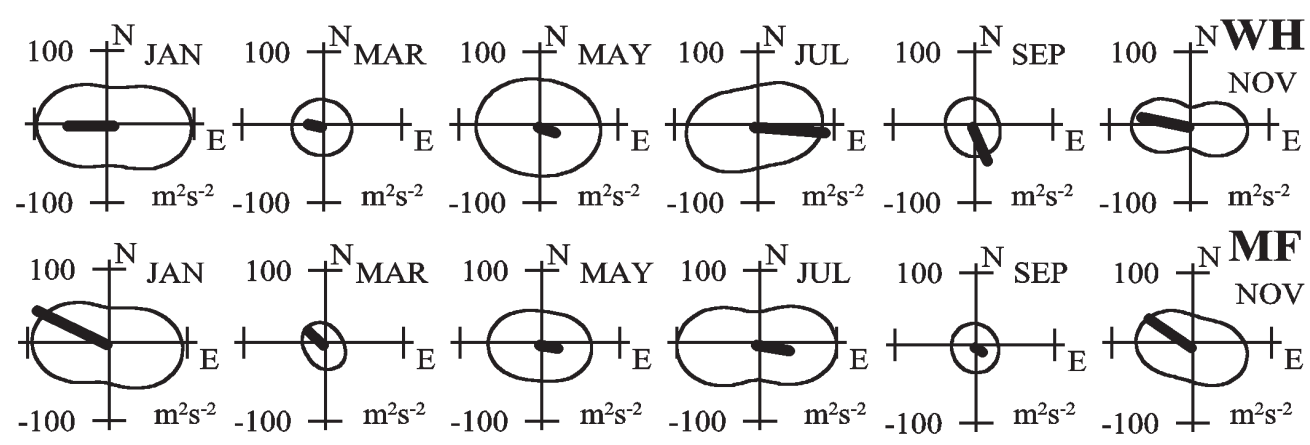

Fig. 3. Dependencies of averaged wind velocity variances on azimuth in horizontal plane for WH (top) and MF (bottom) components at the altitude $70 \mathrm{~km}$. Thick lines show vectors of wave momentum flux $\mathbf{F}_{m} \times 50$

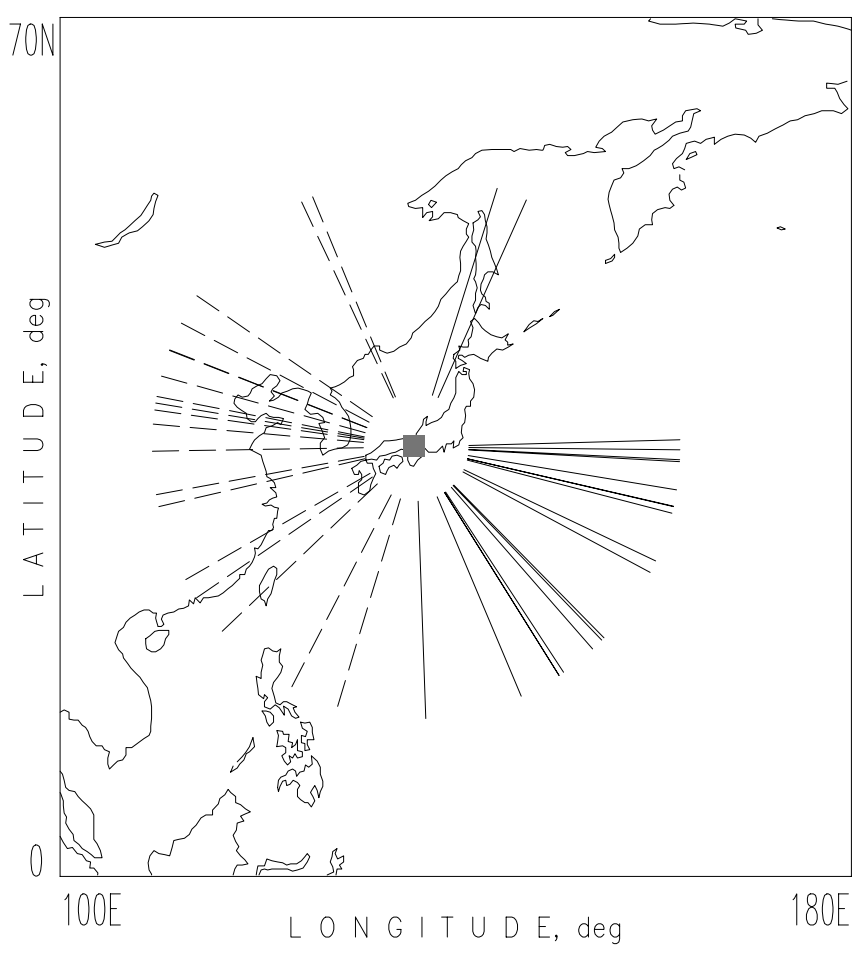

Fig. 4. Directions of averaged wave momentum fluxes reaching the altitudes 70 and $75 \mathrm{~km}$ in both $W H$ and $M F$ frequency bands over Shigaraki during winter (solid lines) and summer (dashed lines) months

intensities and momentum fluxes have magnitudes comparable with corresponding summer values. Also Fig. 2 shows that respective horizontal IGW intensities and momentum fluxes for $W H$ and $M F$ components are comparable to each other. Intensity of the vertical beam wind variance is larger for $W H$ component. Figure 2 shows that for all represented quantities the standard deviations of winter values are generally larger than that in other seasons.

Figure 3 represents distributions of average IGW wind variances along different directions in horizontal plane at altitude $70 \mathrm{~km}$. As was shown by Ebel et al. (1987) and Gavrilov et al. (1995), these distributions are ovals in form. Thick lines in Fig. 3 represent vectors of momentum fluxes, the magnitudes and azimuths of which are calculated using Eq. (6). One can see seasonal variations of size and inclinations of the intensity oval axes. Having zonal and meridional components of IGW momentum flux, we can obtain azimuths, $\varphi_{m}$, of predominant wave momentum flux shown in Fig. 3.

Directions of IGW momentum fluxes in Fig. 3 have seasonal variations. The mean momentum fluxes are directed mainly to the northwest in winter and around an eastward direction in summer. Figure 4 shows schematic geographic map with directions of average IGW momentum fluxes for winter and summer months for both $W H$ and $M F$ frequency bands at both altitudes 70 and $75 \mathrm{~km}$. Assuming that the main portion of IGW momentum propagates from tropospheric sources, one can see from Fig. 4 that the main momentum fluxes propagate to the mesosphere above the MU radar from sources located towards the tropical and subtropical Pacific in winter and the continental part of Asia in summer. Therefore, seasonal and inter-annual behaviour of IGW sources in these regions can form peculiarities of seasonal and inter-annual variations of IGW activity observed in the mesosphere above the MU radar (see Sect. 3.3 and discussion later).

\subsection{Dependence on the mean wind}

Figure 5 reveals dependencies of monthly mean IGW characteristics on the mean zonal, $u_{0}$, and meridional, $v_{0}$, wind. One can see that IGW intensities generally increase with the increase in the magnitude of zonal wind. In Fig. 5 negative and positive $u_{0}$ correspond generally to summer and winter, respectively. The rate of IGW intensity increase with $\left|u_{0}\right|$ is larger in summer than in winter in all the plots of Fig. 5 except for $\overline{w^{\prime 2}}$ for $M F$ component. Scattering of experimental points in Fig. 5 is generally larger in summer than in winter.

Zonal IGW momentum flux in Fig. 5 has a negative trend versus $u_{0}$ so that the mean momentum flux is directed opposite to the mean zonal wind as shown in Fig. 2. The same negative trend is seen in Fig. 5 for meridional IGW momentum flux versus $v_{0}$ for $M F$ component with periods 1-6 h. For shorter-period WH component the trend is weaker with a tendency to be positive (see Fig. 5). A reason for that could be explained by the theory of Doppler shifting (spreading) of IGW spectrum (Fritts and VanZandt, 1987; Hines, 1991). According to the theory, each component of IGW spectrum propagates in the wind field produced by both the mean wind and larger-scale waves. These waveinduced winds could reduce the influence of the mean 

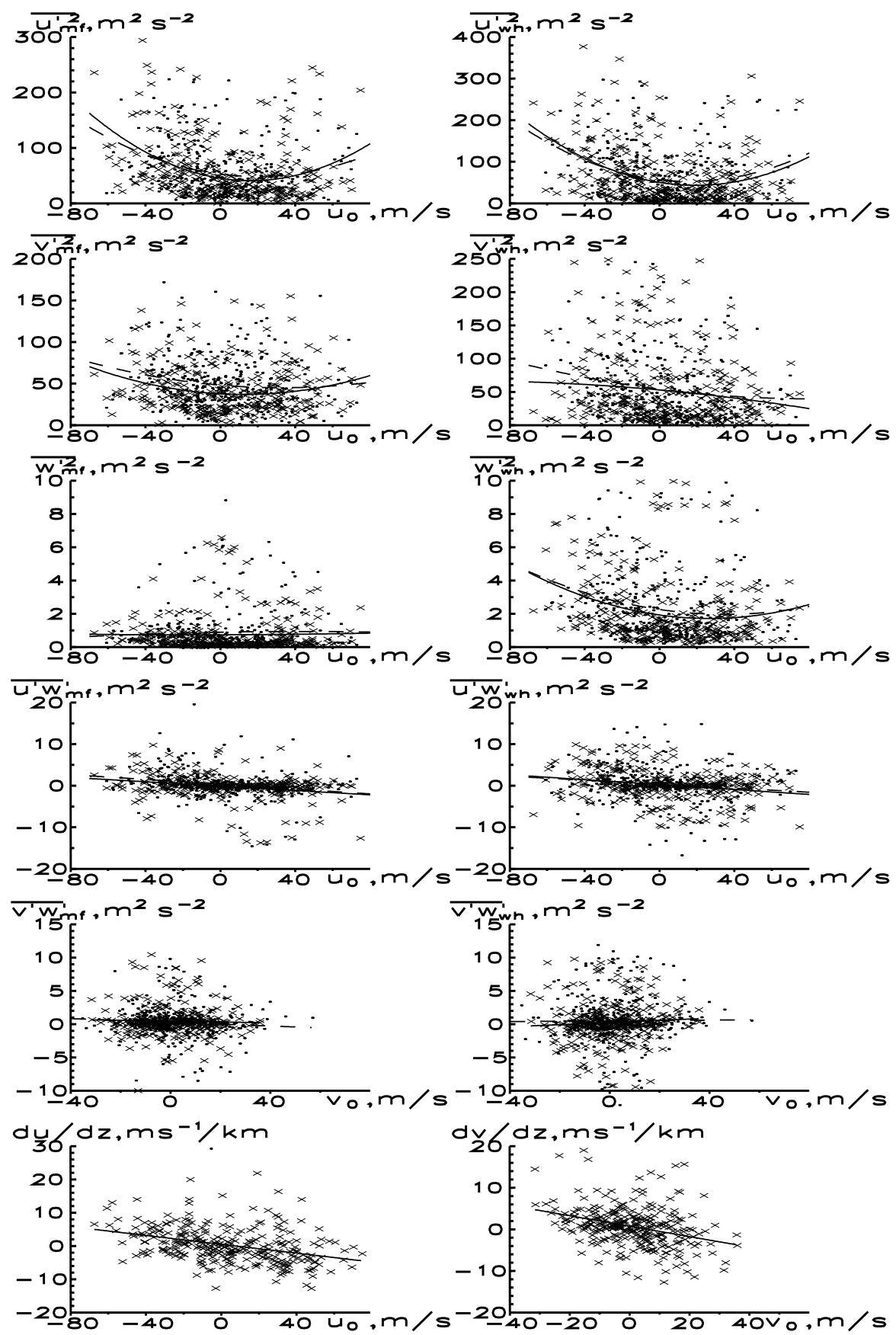

Fig. 5. Daily wind variances and wave momentum fluxes versus the mean wind for $M F$ (left) and $W H$ (right) components averaged over $6-\mathrm{km}$ thick layers centered at altitudes $70 \mathrm{~km}$ (crosses and thick lines) and $75 \mathrm{~km}$ (dots and thin lines). For regression 2nd order polynoms are used on three upper rows of plots and linear function on other plots

wind. For short-period IGWs the influence of the waveinduced winds is larger than for long-period components. Also, the mean meridional winds are generally smaller than zonal winds. Therefore, the influence of the mean wind can be reduced to larger extent in the case of short-period IGWs and of weaker meridional winds in accordance with Fig. 5.

It is presumed that IGWs propagating in the atmosphere could break and generate turbulence (Fritts, 1984). Therefore, a portion of irregular winds in the middle atmosphere could be of turbulent origin and we can expect that $\overline{u^{\prime} w^{\prime}} \sim-\partial u_{0} / \partial z$ and $\overline{v^{\prime} w^{\prime}} \sim-\partial v_{0} / \partial z$ in accordance with theory of turbulent viscosity (Monin and Yaglom, 1971). Figure 6 shows dependencies of monthly mean components of IGW momentum flux versus vertical gradient of zonal and meridional velocity, which were calculated from differences of the mean winds at altitudes 70 and $75 \mathrm{~km}$. It is seen that in all plots of Fig. 6 we have a positive trend of IGW momentum fluxes with the mean wind gradients, which is opposite to our expectations.

Observed altitudes $70-75 \mathrm{~km}$ are located in the upper part of strato-mesospheric jet. Magnitudes of the mean wind usually decrease in altitudes here. Therefore, we can expect that stronger strato-mesospheric jet and higher wind speed at $70 \mathrm{~km}$ should correspond to larger magnitude of wind speed differences in vertical situation. In winter, the mean wind at $70 \mathrm{~km}$ is positive, wind 


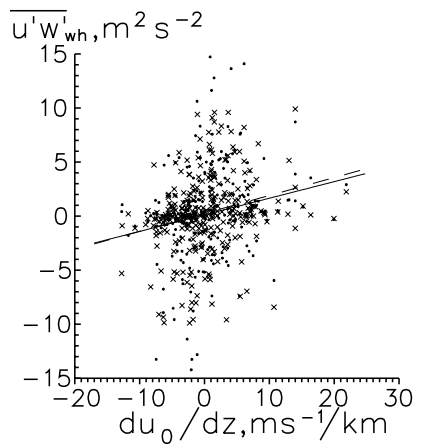

$\overline{u^{1} w_{m f}^{1}}, m^{2} s^{-2}$
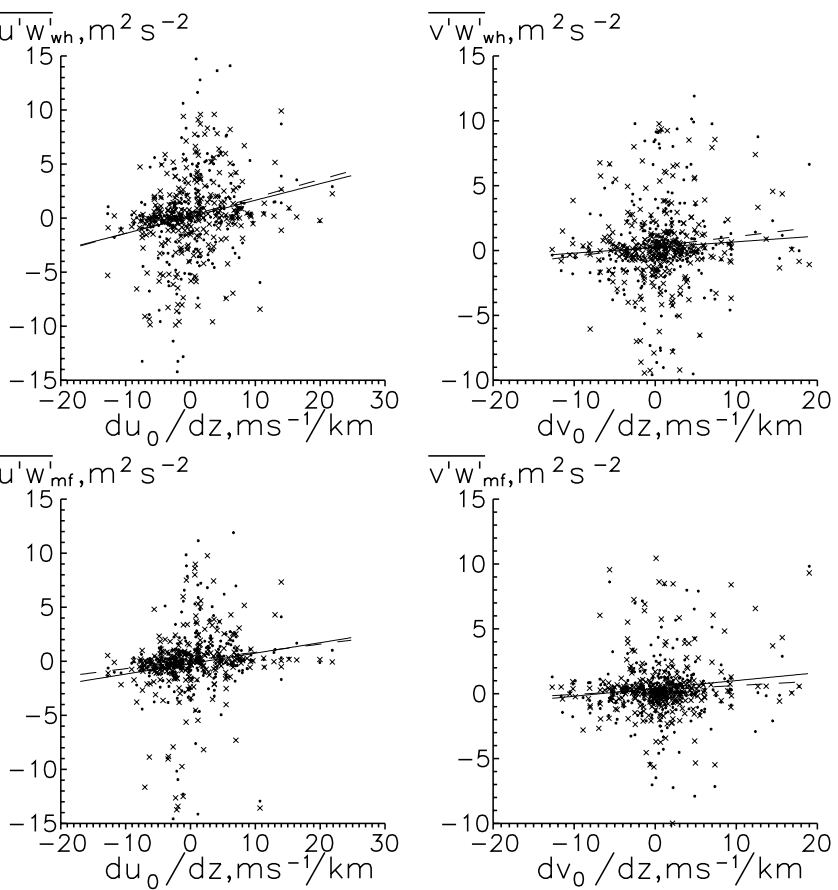

Fig. 6. Daily values of wave momentum fluxes versus vertical gradients of the mean wind for $M F$ (upper) and $W H$ (bottom) components averaged over $6-\mathrm{km}$ thick layers centred at altitudes $70 \mathrm{~km}$ (crosses and solid lines) and $75 \mathrm{~km}$ (dots and dashed lines)

difference between 75 and $70 \mathrm{~km}$ is negative, and larger values of the mean wind at $70 \mathrm{~km}$ correspond to smaller vertical wind gradients taking account their signs. In summer, the mean wind at $70 \mathrm{~km}$ is negative, wind difference between 70 and $75 \mathrm{~km}$ is positive, and again larger negative values of the mean wind at $70 \mathrm{~km}$ correspond to its smaller magnitude and to smaller vertical wind gradient. Therefore, generally a larger mean wind at $70 \mathrm{~km}$ corresponds to smaller vertical wind gradients, if we take into account different signs of mean wind speed and its vertical gradients in winter and summer. The lower plots of Fig. 5 confirm this assumption and show dependencies of vertical wind gradients versus components of the mean wind at the altitude $70 \mathrm{~km}$. Comparing these plots with other plots in Fig. 5, we can see that the wave momentum fluxes and vertical wind gradients both depend on the mean wind. Therefore, positive trends of momentum fluxes versus the mean wind gradients in Fig. 6 may simply correspond to the negative trend of the momentum fluxes versus the mean winds in Fig. 5. Hence positive trends of Fig. 6 could indicate that may be produced by motions other than turbulence (say, IGWs) or the turbulent viscosity at scales of our $M F$ and $W H$ frequency bands cannot be described by simple turbulent relations for microscale turbulence mentioned.

\subsection{Seasonal variations in different years}

To study changes in the seasonal variations of IGW characteristics, we divide the data of 12-year MU radar measurements into three 4-year sets. Figure 7 represents seasonal variations of the mean wind and IGW characteristics averaged over each of these 4-year sets. One can see that seasonal variations of IGW characteristics are different in different time periods. The main differences are in IGW intensity and momentum fluxes during winter.

In 1986-1989 the winter maximum of zonal and meridional IGW intensity was smaller than the summer maximum (see Fig. 7). This is consistent with previous studies of IGW characteristics for these years (Tsuda et al., 1990; Nakamura et al., 1993a, b). Figure 7 shows that during 1990-1993 the winter maximum of horizontal IGW intensity was larger than the summer maximum. After that, in 1994-1997, the winter maximum became smaller again (see Fig. 7). We can see similar behaviour in Fig. 7 for magnitudes of zonal and meridional IGW momentum fluxes.

Seasonal variations of the zonal mean wind in Fig. 7 also vary in different years, having smaller January magnitudes in 1990-1993 compared to other periods. This corresponds to month by month wind variations over the MU radar presented by Gavrilov et al. (1999). Summer values of zonal IGW intensities and momentum fluxes are more stable at different time intervals presented in Fig. 7. The main reasons for the seasonal variations of IGW characteristics could be variations of IGW source intensity and IGW interactions with the mean wind and temperature profiles during wave propagation (Eckermann, 1995; McLandress, 1998). Numerical modelling of seasonal variations of IGW intensity in the atmosphere over the MU radar by Gavrilov and Fukao (1999) reveals an important role of tropospheric hydrodynamic IGW sources. It is shown in Sect. 3.1 that IGWs carrying major momentum fluxes could reach the mesosphere over the MU radar from different regions of the troposphere in winter (tropical and subtropical Pacific) and in summer (continental Asia). Interannual variations of IGW sources in these regions can influence the observed changes of seasonal variations of wave activity and influence the changes of the mean circulation of the middle atmosphere due to wave-mean flow interactions (see discussion).

\section{Discussion}

Average intensities of IGW variations of zonal and meridional velocity and wave momentum fluxes shown in Fig. 2 have the same orders of magnitude for the medium frequency, $M F$, and high frequency, $W H$, components. At the same time, the spectral band of $W H$ frequency filter is several times larger than the spectral band of $M F$ filter (see Fig. 1). This means that IGWs with lower frequencies have much larger amplitudes than higher-frequency harmonics (see Gavrilov et al., 1996, 1997). Therefore, a much narrower frequency band of lower-frequency IGWs can make contributions to wave intensity and momentum fluxes, which are compatible with the contributions from much wider spectral range of higher-frequency components. 

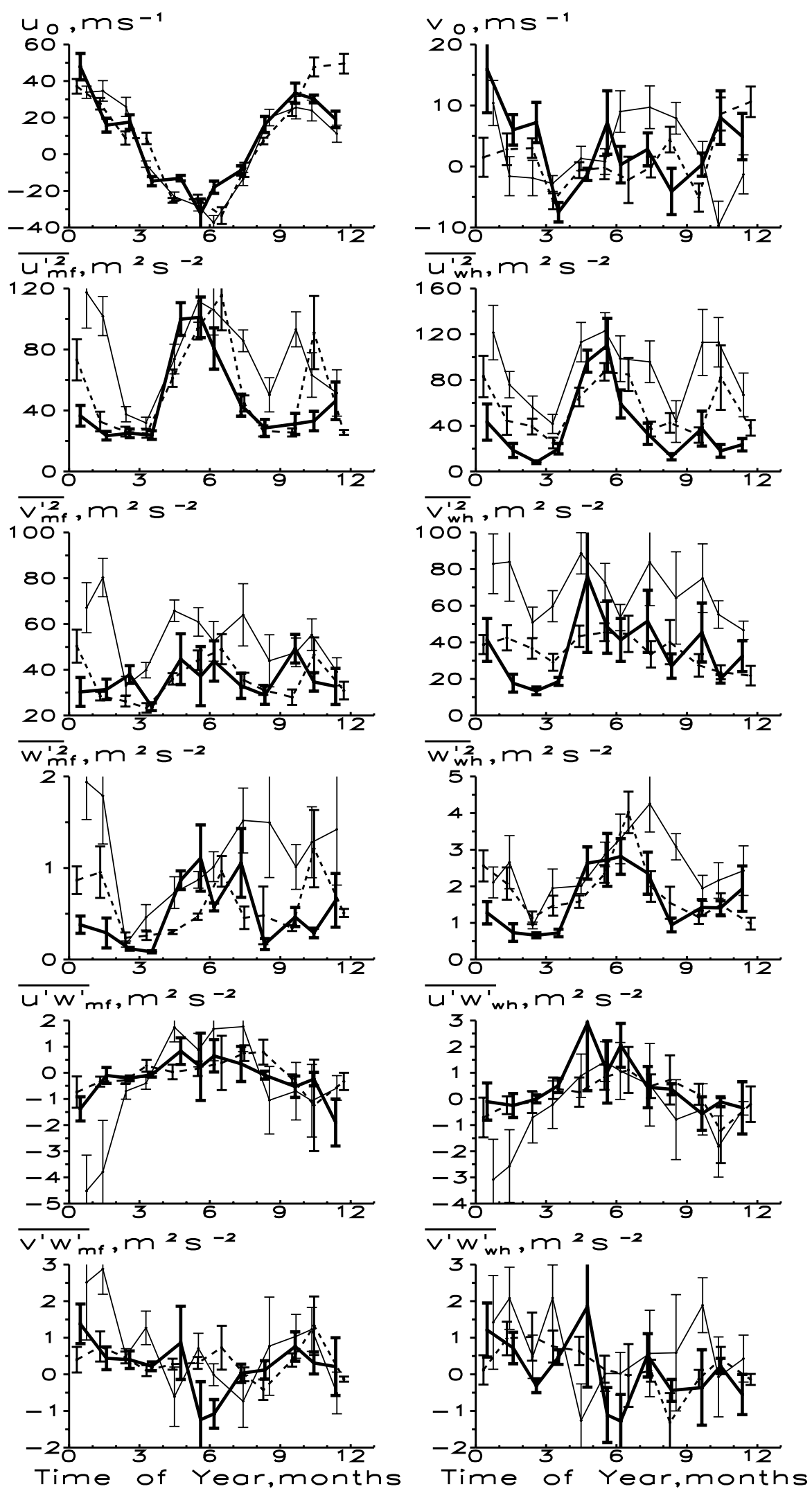

Fig. 7. Same as Fig. 2, but averaged for altitudes 65-80 km and over 1986-1989 (dashed lines), over 1990-1993 (thin lines), and over 1994-1997 (thick lines)

Similar results concerning the compatibility of intensities and momentum fluxes produced by lower- and higher-frequency IGWs were obtained previously by Nakamura et al. (1993a, 1996).
The results presented in Fig. 7 show substantial interannual changes in seasonal variations of IGW intensity and momentum fluxes. Previous studies of IGWs from the MU radar data have been made on the 
basis of measurements in 1986-1989 (Tsuda et al., 1990; Nakamura et al., 1993a, b). The main results of these studies of prevailing summer maximum and secondary winter maximum are in agreement with corresponding curves of Fig. 7. However, this result is not universal and we can have different magnitudes of winter and summer maxima in different years (see Fig. 7). The averages for the 12 year seasonal variations shown in Fig. 2 have comparable magnitudes of the winter and summer maxima.

Considering the directions of main momentum fluxes presented in Fig. 4, the fact that atmospheric IGW spectrum is very broad and consists of many individual wave packets coming from different sources should be considered. There have been a number of studies of IGW directions in the middle atmosphere (Ebel et al., 1987; Nakamura et al., 1993b; Hall et al., 1995). Gavrilov et al. (1996) made a statistical analysis of directions of horizontal wave vector and momentum fluxes produced by such individual IGWs. These results show that distributions of IGW azimuths are close to isotropic with a small predominance in the numbers of waves propagating in some prevailing directions. Therefore, the directions shown in Fig. 4 do not presumably reflect the directions of propagation of the majority of IGW spectral components.

On the other hand, IGWs propagating in different directions could have different amplitudes and magnitudes of wave momentum fluxes. Theoretical estimations and numerical modelling (Gavrilov, 1997) show that IGWs propagating in the direction of the mean wind have smaller vertical wavelengths and larger dissipation than analogous IGWs propagating opposite to the mean wind. The net IGW momentum flux is a vector sum of momentum fluxes produced by individual IGW components. Therefore, the mentioned dissipation of downstream IGWs can explain the predominance of momentum fluxes directed opposite to the mean wind, as is shown in Figs. 4, 5 and in previous studies (Vincent and Fritts, 1987; Tsuda et al., 1990; Nakamura et al. 1993a; Gavrilov et al., 1997). Hence the directions shown in Fig. 6 probably reflect the directions of arriving IGWs with the largest amplitudes and momentum fluxes at different seasons.

Figure 7 shows the strong variability of seasonal cycles of IGW intensity and momentum fluxes in different years. The reasons for that could be the changes in the strength of IGW sources and changes in wave filtering by the mean wind and temperature during their propagation to the mesopause region. A reason for IGW activity changes, which should be also considered, is the solar activity, which had a maximum in 1989-1991. Some previous studies (Sprenger and Schminder, 1969; Greisiger et al., 1987; Manson and Meek, 1991; Namboothiri et al., 1993; 1994; Gavrilov et al., 1995) show trends of middle atmospheric winds and IGW intensity versus solar activity. However, usually, such estimations show smaller effects of solar activity on IGW intensity than we see in Fig. 7. Therefore, we can assume the existence of different reasons for IGW interannual variations, which are superimposed on the effects of solar activity.

Numerical modelling by Gavrilov and Fukao (1999) shows that IGW intensity near the mesopause is controlled by the intensity of wave sources and by the conditions of IGW propagation through the mean fields of wind and temperature. Therefore, interannual variations of the mean wind and temperature in the middle atmosphere could produce interannual changes of IGW activity near the mesopause. Unfortunately, at present we have no clear picture of interannual variations of the mean wind and temperature in the entire atmosphere around the MU radar. Additional studies are needed for better understanding the contribution of IGW propagation conditions into observed changes of IGW activity near the mesopause. It is known that the prevailing conditions in the stratosphere are more stable during summer, because planetary waves propagated from the troposphere are weaker in summer than in winter. This may result in greater stability of summer wind variations in different years, which one can see in Fig. 7.

We may also anticipate interannual changes of IGW sources in the atmosphere. Figure 4 shows that most strong IGW momentum fluxes come from the sources located over continental Asia in summer. From Fig. 7 we can see that the summer maximum of IGW intensity is more stable than the winter maximum. Therefore, we can expect that the IGW sources in summer are more stable than the winter sources.

In winter major IGW momentum fluxes reach the mesosphere above the MU radar from sources located over the tropical and subtropical Pacific (see Fig. 4). Dynamical conditions in the lower atmosphere are not stable in that region. For example, a substantial influence on the atmospheric dynamics is made by interannual increases and decreases of ocean surface temperature known as El Niño and La Niña, respectively. Usually such events are attributed to the equatorial Pacific, but some indications are available that correlated changes of surface temperature can exist at middle and even high latitudes as well (Bailey, 1998).

According to existing views (Gage et al., 1996), the effects of El Niño and La Niña can change the intensity of wave generation in the Pacific lower atmosphere and produce interannual variations of the intensity of waves reaching the mesosphere from below. Figure 7 shows that IGWs coming from the Pacific can dominate over the site of the MU radar only in winter. Therefore, we can anticipate larger effects of changes in IGW generation over the Pacific at this season. Larger interannual variability of the winter maximum of IGW intensity seen in Fig. 7 can also be produced by larger intensity of planetary waves in the middle atmosphere in winter than in summer, which can influence the IGW propagation. One should keep in mind, also, that the MU radar observations are performed only $4-5$ day a month. Data gaps may further decrease amount of data (especially in a winter weak echo) and produce additional variability of observed parameters. 


\section{Conclusion}

We have made a study of averaged seasonal variations of wind fluctuation intensities and vertical fluxes of horizontal momentum produced by IGWs at the altitudes $65-80 \mathrm{~km}$ using the observational data from the MU radar in 1986-1997. Simple numerical filters are used to separate IGWs with periods $0.2-1 \mathrm{~h}$ and $1-6 \mathrm{~h}$. IGW intensity has its maxima in winter and in summer. The winter maximum has larger interannual variations. The mean wave momentum flux is directed to the west in winter and to the east in summer, opposite to the mean wind direction in the middle atmosphere.

Directions of predominant momentum fluxes show that strongest IGWs come to the mesosphere over the MU radar from sources located over the continental Asia in summer and from the tropical and subtropical Pacific in winter. Interannual changes in the strength of IGW sources and conditions of their propagation in the atmosphere may be the reasons for the observed substantial interannual changes in seasonal variations of IGW intensity and momentum fluxes.

Acknowledgements. The authors thanks H. Luce, R. Reddi, J. Röttger, and M. Yamamoto for useful discussions and interest in this study. The MU radar belongs to and is operated by the Radio Atmospheric Science Center of Kyoto University.

Topical Editor F. Vial thanks G. D. Nastrom and R. Wilson for their help in evaluating this paper.

\section{References}

Andrews, D. G., J. R. Holton, and C. B. Leovy, Middle atmosphere dynamics, Academic Press, New York, 1987.

Bailey, J. S., Temperature anomalies in high northerly latitudes and their link with the El Ninõ/Southern Oscillation, Ann. Geophysicae, 16, 1501-1512, 1998.

Ebel, A., A. H. Manson, and C. E. Meek, Short period fluctuations of the horizontal wind measured in the upper middle atmosphere and possible relationship to internal gravity waves, J. Atmos. Terr. Phys., 49, 385-401, 1987.

Eckermann, S. D., On the observed morphology of gravity-wave and equatorial-wave variance in the stratosphere, J. Atmos. Terr. Phys., 57, 105-134, 1995.

Fritts, D. C., Gravity wave saturation in the middle atmosphere: a review of theory and observations, Rev. Geophys. Space Phys., 22, 275-308, 1984.

Fritts, D. C., and T. E. VanZandt, Effects of Doppler shifting on the frequency spectra of atmospheric gravity waves, J. Geophys. Res., 92, 9723-9732, 1987.

Fritts, D. C., and R. A. Vincent, Mesospheric momentum flux studies at Adelaide, Australia: observations and a gravity wavetidal interaction model, J. Atmos. Sci., 44, 605-619, 1987.

Fukao, S., T. Sato, T. Tsuda, S. Kato, M. Inaba, and I. Kimura, VHF Doppler radar determination of the momentum flux in the upper troposphere and lower stratosphere: comparison between the tree- and four-beam methods, itref J. Atmos. Oceanic Tech., 5, 57-69, 1988.

Gage, K. S., J. R. McAfee, and C. R. Williams, On the annual variation of tropospheric zonal winds observed above Christmas Island in the central equatorial Pacific, J. Geophys. Res., 101, 15 061-15 070, 1996.

Gavrilov, N. M., Parametrization of momentum and energy depositions from gravity waves generated by tropospheric hydrodynamic sources, Ann. Geophysicae, 15, 1570-1580, 1997.
Gavrilov, N. M., and S. Fukao, A comparison of seasonal variations of gravity wave intensity observed by the MU radar with a theoretical model, J. Atmos. Sci., 56, 3485-3494, 1999.

Gavrilov, N. M., A. H. Manson, and C. E. Meek, Climatological monthly characteristics of middle atmosphere gravity waves (10 min-10 hr) during 1979-1993 at Saskatoon, Ann. Geophysicae, 13, 285-295, 1995.

Gavrilov, N. M., S. Fukao, T. Nakamura, T. Tsuda, M. D. Yamanaka, and M. Yamamoto, Statistical analysis of gravity waves observed with the MU radar in the middle atmosphere: 1 . Method and general characteristics, J. Geophys. Res., 101, 29 511-521, 1996.

Gavrilov, N. M., S. Fukao, T. Nakamura, and T. Tsuda, Statistical analysis of gravity waves observed with the MU radar in the middle atmosphere: 2 . Waves propagated in different directions, J. Geophys. Res., 102, 13 433-13 440, 1997.

Gavrilov, N. M., S. Fukao, and T. Nakamura, Peculiarities of interannual changes in the mean wind and gravity wave characteristics in the mesosphere over Shigaraki, Japan, Geophys. Res. Lett., 26, 2457-2460, 1999.

Greisiger, K. M., R. Schminder, and D. Kurschner, Long-period variations of wind parameters in the mesopause region and the solar cycle dependence, J. Atmos. Terr. Phys., 49, 281-285, 1998.

Hall G. E., C. E. Meek, and A. H. Manson, Hodograph analysis of mesopause region winds observed by three MF radars in the Canadian Prairies, J. Geophys. Res., 100, 7411-7421, 1995.

Hines, C. O., The saturation of gravity waves in the middle atmosphere, 2. Development of Doppler-spread theory, J. Atmos. Sci., 48, 1360-1379, 1991.

Hirota, I., Some problems relating to the observed characteristics of gravity waves in the middle atmosphere, NATO ASI Series, 150, Gravity wave processes, their parametrization in global climate models, Springer, New York Berlin Heidelberg, 1-5, 1997.

Manson, A. H., and C. E. Meek, The effects of geomagnetic disturbances and atmospheric tides upon middle atmosphere winds and MF radar scatter at Saskatoon $\left(52^{\circ} \mathrm{N}, 107^{\circ} \mathrm{W}, 61^{\circ}\right.$ geomagnetic, J. Geophys. Res., 96, 915-926, 1991.

Manson, A. H., and C. E. Meek, Characteristics of gravity waves $\left(10\right.$ min-6 hour) at Saskatoon $\left(52^{\circ} \mathrm{N}, 107^{\circ} \mathrm{W}\right)$ observed by the phase coherent medium frequency radar, J. Geophys. Res., 98, 20 357-20 367, 1993.

McLandress, C., On the importance of gravity waves in the middle atmosphere and their parametrization in general circulation models, J. Atmos. Sol. Terr. Phys., 60, 1357-1383, 1998.

Monin, A. S., and A. M. Yaglom, Statistical fluid mechanics, 1, MIT Press, Cambridge, MA, 1971.

Nakamura, T., T. Tsuda, M. Yamamoto, S. Fukao, and S. Kato, Characteristics of gravity waves in the mesosphere observed with the middle and upper atmosphere radar, 1 Momentum flux, J. Geophys. Res., 98, 8899-8910, 1993a.

Nakamura, T., T. Tsuda, M. Yamamoto, S. Fukao, and S. Kato, Characteristics of gravity waves in the mesosphere observed with the middle and upper atmosphere radar, 2 Propagation direction, J. Geophys. Res., 98, 8911-8923, 1993 b.

Nakamura, T., T. Tsuda, S. Fukao, A. H. Manson, C. E. Meek, R. A. Vincent, and I. M. Reid, Mesospheric gravity waves at Saskatoon $\left(52^{\circ} \mathrm{N}\right)$, Kyoto $\left(35^{\circ} \mathrm{N}\right)$, and Adelaide $\left(35^{\circ} \mathrm{S}\right)$, J. Geophys. Res., 101, 7005-7012, 1996.

Namboothiri, S. P., A. H. Manson, and C. E. Meek, Variations of mean winds and tides in the upper middle atmosphere over solar cycle, Saskatoon, Canada, $52^{\circ} \mathrm{N}, 107^{\circ} \mathrm{W}$, J. Atmos. Terr. Phys., 55, 1325-1334, 1993.

Reid, I. M., Some aspects of Doppler radar measurements of the mean and fluctuating components of the wind field in the upper middle atmosphere, J. Atmos. Terr. Phys., 49, 467-484, 1987.

Sprenger, K., and R. Schminder, Solar cycle dependence of winds in the lower ionosphere, J. Atmos. Terr. Phys., 31, 217-221, 1969. 
Tsuda, T., Y. Murayama, M. Yamamoto, S. Kato, and S. Fukao, Seasonal variations of momentum flux in the mesosphere observed with the MU radar, Geophys. Res. Lett., 17, 725728,1990

Vincent, R. A., Gravity wave motions in the mesosphere, J. Atmos. Terr. Phys., 46, 119-128, 1984.
Vincent, R. A., and D. C. Fritts, A climatology of gravity wave motions in the mesopause region at Adelaide, Australia, J. Atmos. Sci., 44, 748-760, 1987.

Vincent, R. A., and I. M. Reid, HF Doppler measurements of mesospheric gravity wave momentum fluxes, J. Atmos. Sci., 40, 1321-1333, 1983. 